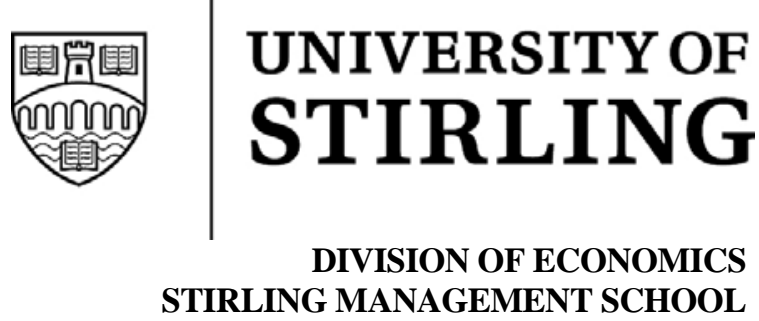

\title{
The effects of rent seeking over tradable pollution permits
}

Nick Hanley

Ian A. MacKenzie

Stirling Economics Discussion Paper 2009-12

May 2009

Online at http://www.economics.stir.ac.uk 


\title{
The effects of rent seeking over tradable pollution
} permits

\author{
Nick Hanley $^{a}$ and Ian A. MacKenzie ${ }^{b, *}$ \\ ${ }^{a}$ Department of Economics, University of Stirling, Scotland, UK, FK9 4LA. \\ ${ }^{b}$ Center for Economic Research (CER), ETH Zürich, 8092 Zürich, Switzerland.
}

\begin{abstract}
The establishment of a tradable permit market requires the regulator to select a level of aggregate emissions and then distribute the associated permits (rent) to specific groups. In most circumstances, these decisions are often politically contentious and frequently influenced by rent seeking behaviour. In this paper, we use a contest model to analyse the effects of rent seeking effort when permits are freely distributed (grandfathered). Rent seeking behaviour can influence both the share of permits which an individual firm receives and also the total supply of permits. This latter impact depends on the responsiveness of the regulator to aggregate rent seeking effort. Using a three-stage game, we show that rent seeking can influence both the distribution of rents and the ex post value of these rents, whilst welfare usually decreases in the responsiveness of the regulator.

Keywords: tradable permit market, rent seeking, initial allocation

JEL classification numbers: D72, D78, Q53
\end{abstract}

\footnotetext{
${ }^{*}$ Corresponding author: E-mail address: imackenzie@ethz.ch (I. MacKenzie); Tel: +41 4463204 68; Fax: +41446321362.
} 


\section{Introduction}

Tradable pollution markets have become an increasingly mainstream regulatory tool for controlling pollution. Since Montgomery (1972), economists have known that under certain conditions, such markets can achieve an efficient (that is, cost-minimising) allocation of pollution control efforts across polluters, irrespective of the initial allocation of permits by a regulator. This is because post-allocation trading will allow all potential gains from trades to be realised. However, the initial allocation of permits has become a matter of political debate, and of increasing academic interest, since firms' gains and losses can in the real world depend on this initial allocation. Moreover, since permits are valuable, allocation creates rents, over which firms can be expected to compete ex ante by rent seeking. In many existing tradable permit markets, regulators' decisions over the distribution and absolute level of emissions have often been influenced by interested parties (see, for example, Svendsen (2005)). ${ }^{1}$ This influence, in the form of rent seeking, is seen as socially unproductive and often as a significant and sustained problem.

An important question is thus how rent seeking strategies are determined in tradeable permit markets, how this influences social welfare, and whether this depends on the degree to which a regulator allows rent seeking to determine both the distribution and absolute level of these rents. Our conclusion is that when regulators are responsive to aggregate rent seeking then rent seeking strategies for tradable permits differ significantly from standard (non-tradeable) rents. This is a direct result of firms having the ability to trade pollution permits which produces an equilibrium price effect. When the regulator's responsiveness to aggregate rent seeking increases we find this usually results in a decrease in welfare, so that the damage caused by the increase in aggregate emissions outweighs any decrease in rent seeking from a reduction in the permit value.

In this paper we use a contest framework to analyse rent seeking. A typical contest allows agents to invest in effort in order to win a prize (Congleton et al., 2008). This approach has been used successfully in many areas such as litigation, political campaigning, labour market promotions, conflicts, R\&D patent races and sports events (Konrad, 2009). One important application of contest theory is rent seeking. Starting from the seminal works of Krueger

\footnotetext{
${ }^{1}$ For the $\mathrm{SO}_{2}$ market see http://www.epa.gov/airmarkets/basic.html and for the EU-ETS: http://ec.europa.eu/environment/climat/emission.htm. Anecdotal evidence exists for the existence of lobbying (from individual senators) in the US $\mathrm{SO}_{2}$ trading scheme (Ellerman et al. 2000) and by industry in the European Union Emissions Trading Scheme (EU-ETS) (Svendsen, 2005; Ellerman et al. 2007).
} 
(1974), Posner (1975) and Tullock (1980), a substantial body of work has focused on rent dissipation issues, where the total rents available for capture across all agents are taken as fixed (for surveys of the literature, see Nitzan, 1994; Congleton et al., 2008; Konrad, 2009). However, for our model, we allow the total rent to be endogenously determined by aggregate rent seeking effort (Chung, 1996; Shaffer, 2006). In the same vein, Chung (1996) extends a Tullock-style rent seeking contest model to include a rent that is endogenously determined by aggregate efforts and finds that the extended contest generates excessive effort levels which are socially wasteful. More recently, Shaffer (2006) finds that effort levels tend to adjust in the direction of the change in the rent. For example, when the rent is "productive" (where the rent is increasing in aggregate efforts), agents tend to invest more effort in rent seeking. However, this literature typically assumes that rents are non-tradable, which limits the insights one can draw when considering tradable pollution permit markets.

A tradable permit market involves an ex post reallocation of rents. It has long been understood that such an ex post reallocation of emission rights can produce an efficient allocation of emission reductions among polluters (Montgomery, 1972). Few authors, however, have considered rent seeking contests when ex post reallocation is not just possible but essential to the operation of the policy instrument. Dari-Mattiacci et al. (2009) and Sui (2009) find that although contests are allocatively efficient, effort levels tend to increase when ex post reallocation is permitted. However, it is not clear how these rents differ from standard rents in terms of agents' rent seeking strategies and regulatory responses. In the context of tradable pollution permit markets, Lai (2007) has investigated the social welfare consequences of firms and environmental groups lobbying over the determination of an aggregate emissions cap and finds allocating freely may be more efficient than auctioning. However, the incentives for firms to rent-seek for their own private benefit (to increase their own individual share of permits at the expense of rival firms) is not considered by Lai.

In this paper, we introduce a contest where polluting firms have the option to invest in rent seeking effort that has the potential to increase their own permit allocation within a tradable permit market and, simultaneously, the aggregate supply of permits from the regulator (i.e. political pressure to increase individual and aggregate level emissions). We allow the regulator to select a provisional aggregate emissions target (for example, by announcing draft 
legislation) which can be subsequently influenced by firms' rent seeking effort. We provide cases where the regulator views rent seeking as 'purely' socially wasteful and, alternatively, where the regulator obtains political contributions from rent seekers. We show the incentives behind firms' rent seeking effort in a tradable permit market and compare this to a standard rent seeking framework. Our focus is thus on how the market value of the ex post reallocated rent, which is endogenously determined by the marginal costs of participating firms and the aggregate supply of permits (which may be determined by rent seeking itself), alters rent seeking behaviour and social welfare. We find differences in firms' rent seeking choices compared to a conventional contest. We see that a fundamental aspect of firms' incentives to rent-seek depends on the market value of the permits, that is, the value of the ex post reallocated rents.

This paper focuses on rent seeking for tradable pollution permits, however, the rationale can directly apply to more general contests where the prize won has the ability of being ex post reallocated. The paper is organised as follows. Section 2 introduces the model and provides a benchmark comparison. In Section 3, the firm's optimal choice of emissions is determined. In Section 4, the firm's equilibrium rent seeking strategy is discussed for both an endogenous and exogenously determined rent and aggregate rent seeking effort is then derived. Section 5 investigates the regulator's optimal choice of aggregate emissions and discusses whether alternative responses to rent seeking can be welfare improving. Section 6 provides some policy implications and Section 7 concludes.

\section{The model}

Consider a set of firms $\{1,2, \ldots, n\}$ that participate in a competitive tradable pollution permit market. In this market, permits are initially allocated freely but each firm has the ability to alter the amount of permits it receives from the regulator by investing in rent seeking effort denoted by $s_{i}$ for $i=1,2, \ldots, n .^{2}$ A unilateral increase in firm $i$ 's rent seeking investment will result in

\footnotetext{
${ }^{2}$ Our results are qualitively similar when one considers a hybrid allocation approach where both auctioning and grandfathering can be used (where the rent now available for rent seekers is simply the total allocation minus the permits allocated from the auction). This approach has been advocated by energy companies for the forthcoming US wide cap-and-trade program (Point Carbon, 2009). Furthermore, our results may provide analysis on how firms rent seek for permits where allocation mechanisms use "reserves", energy intensity targets and "safety valves" prior to the beginning of the scheme (Pizer, 2002; Newell et al., 2005). To introduce full auctioning of permits, the distribution of permits can be modelled as a multi-unit auction (see, Krishna, 2002). In this case, rent seeking influences the aggregate level of emissions but not the distribution of permits.
} 
that firm obtaining relatively more permits prior to the beginning of the market. Additionally, we allow for the possibility that aggregate rent seeking effort influences the regulator's final decision when selecting an absolute level for the aggregate emissions cap. That is, market participants can apply political pressure on the regulator to increase the aggregate emissions level. $^{3}$ Therefore, an increase in rent seeking by firm $i$ increases their share of the "pie" and provides pressure to increase the absolute size of the "pie". After the initial distribution of the rents, firms are free to trade and reallocate these permits.

Our model is split into three stages. In stage one, the regulator selects a provisional level of aggregate emissions for the trading permit market denoted by $\tilde{A}$ (such as draft legislation). In stage two, given this information, each firm invests in rent seeking effort $s_{i} \forall i$ to obtain a share of the aggregate emissions which results in a "final" aggregate allocation for the permit market denoted by $A$. In stage three, the market commences and each firm selects a level of pollution to emit in the market.

To model how the provisional aggregate emissions level in stage one differs from the final emissions level in stage two, we introduce an exogenous political "responsiveness" parameter $\mu \in[0, \infty)$ which is common knowledge among all firms and the regulator. ${ }^{4}$ The political responsiveness parameter $\mu$ represents the political and cultural interactions and governance relationship between the regulator and regulated firms. When $\mu=0$ the regulator is unresponsive to aggregate rent seeking and the resulting aggregate emissions cap is simply the provisional aggregate emissions chosen by the regulator $\tilde{A}$. For $\mu>0$, the regulator is responsive to firms' rent seeking efforts. Formally, the final aggregate emissions cap $A$ set by the regulator is determined by

$$
A=\tilde{A} \cdot\left(1+\mu \sum_{i=1}^{n} s_{i}\right)
$$

where the final rent available in the contest is endogenously determined by the regulator's initial draft legislation $\tilde{A}$ and aggregate rent seeking effort $\sum_{i}^{n} s_{i}$. We follow a framework

\footnotetext{
${ }^{3}$ Importantly, this does not require cooperation between market participants. Each participant rent-seeks in order to obtain a permit allocation for themselves. It is only as a result of this accumulated rent-seeking activity that provides pressure on the regulator to increase the aggregate emissions.

${ }^{4}$ The political responsiveness parameter represents the affect of aggregate rent-seeking effort on the regulator's choice of emissions. Even for values of $\mu=0$, rent-seeking effort will continue to determine the distribution among firms. Furthermore, an upper bound on $\mu$ will exist where the responsiveness is sufficiently large to reduce the equilibrium permit price to zero. Negative values of $\mu$ can also be considered, however, this is less realistic for the context of rent-seeking for pollution permits. As Shaffer (2006) explains, allowing for $\mu<0$ results in a destructive contest where the rent decreases in aggregate rent-seeking efforts.
} 
similar to Helm (2003). To solve the subgame perfect Nash equilibrium, we solve the model using backward induction and as a result outline and solve stage three first.

\section{Stage three: firms' choice of equilibrium emissions}

In stage three, the tradable permit market commences and firm $i$ selects a level of emissions. Assuming the equilibrium permit price $p^{*}$ and the level of allocation $a_{i}^{0}$ obtained in stage two is taken as given (and hence the aggregate allocation $A$ finalised in stage two), firm $i$ 's payoff from the tradable permit market is:

$$
\max _{e_{i}} \Pi_{i}=p^{*}\left(a_{i}^{0}-e_{i}\right)-c_{i}\left(e_{i}\right) \quad \text { for all } i=1,2, \ldots, n
$$

where $e_{i}$ is the level of net emissions (inclusive of abatement choices) and $c_{i}\left(e_{i}\right)$ is the abatement cost function where $c_{i}^{\prime}\left(e_{i}\right) \leq 0, c_{i}^{\prime \prime}\left(e_{i}\right) \geq 0$. The term $\left(a_{i}^{0}-e_{i}\right)$ shows firm $i$ 's net supply of permits to the market (which can also be negative). Given the levels of allocation to each firm (and the subsequent equilibrium permit price determined by the aggregate emissions), differentiating (2) with respect to $e_{i}$ yields the following first order condition:

$$
-p^{*}-c_{i}^{\prime}\left(e_{i}\right)=0 \quad \text { for all } i=1,2, \ldots, n
$$

which is solved for $e_{i}^{*}$ and the market clearing condition is given by

$$
\sum_{i=1}^{n} e_{i}=A
$$

The first order condition (3) states the familiar result that each firm will choose a level of emissions to equate their marginal abatement costs with the equilibrium permit price. Condition (4) is the market clearing condition where, in equilibrium, the aggregate emissions must equate to the aggregate supply of permits.

Similar to Helm (2003), we differentiate (3) with respect to $p^{*}$ and (4) with respect to $A$ 
and obtain:

$$
\begin{aligned}
-1-c_{i}^{\prime \prime}\left(e_{i}\right) \frac{\partial e_{i}}{\partial p^{*}} & =0 & & \text { for all } i=1,2, \ldots, n \\
\sum_{i=1}^{n} \frac{\partial e_{i}}{\partial p^{*}} \frac{\partial p^{*}}{\partial A} & =1 & & \text { for all } i=1,2, \ldots, n
\end{aligned}
$$

where substitution yields:

$$
\frac{\partial p^{*}}{\partial A}=-\left[\frac{1}{\sum_{i=1}^{n} \frac{1}{c_{i}^{\prime \prime}\left(e_{i}\right)}}\right]<0
$$

Expression (7) shows that as the aggregate allocation increases, the equilibrium permit price decreases. Note that the extent of this depreciation is based on the slope of firms' marginal abatement costs, where steeper marginal abatement costs result in a larger change in the equilibrium permit price. As will be discussed later in the paper, the relationship in (7) is the key to understanding how rent seeking for ex post reallocated rents (such as pollution permits) differs from standard rents.

\section{Stage two: firms' optimal rent seeking effort}

In this stage, firm $i$ selects a level of rent seeking effort to obtain an initial allocation of permits for the beginning of the tradable permit market in stage three. Let us assume that in stage one $\tilde{A}^{0}$ was chosen by the regulator where each firm knows that the final aggregate emissions cap for the tradable permit market is determined by $\tilde{A}^{0}\left(1+\mu \sum_{i=1}^{n} s_{i}\right)$. This rent seeking, from the view point of society, is unproductive. Formally, we represent the allocation of permits to firm $i$ by:

$$
a_{i}=\left\{\begin{array}{ll}
f\left(s_{i}, s_{-i}\right) A & \text { if } \sum_{i=1}^{n} s_{i}>0 \\
\frac{\tilde{A}}{n} & \text { otherwise }
\end{array} \quad \text { for all } i=1,2, \ldots, n\right.
$$

where $\frac{\partial a_{i}}{\partial s_{i}} \geq 0, \frac{\partial^{2} a_{i}}{\partial s_{i}^{2}} \leq 0, s_{i}$ is firm $i$ 's rent seeking effort, $s_{-i}=\sum_{j \neq i}^{n} s_{j}, A$ is the aggregate emissions level given in (1) with $\tilde{A}=\tilde{A}^{0}$. From (8), $f\left(s_{i}, s_{-i}\right)$ is a share function with the 
following properties (See, for example a contest success function, Skaperdas, (1996)): ${ }^{5}$

$$
\frac{\partial f}{\partial s_{i}}>0, \frac{\partial^{2} f}{\partial s_{i}^{2}}<0 \frac{\partial f}{\partial s_{-i}}<0, \sum_{i=1}^{n} f\left(s_{i}, s_{-i}\right)=1 \quad \text { for all } i=1,2, \ldots, n
$$

From (1), (8) and (9) observe that $a_{i}$ is increasing in $s_{i}$ and decreasing in $s_{-i}$. As shown above, rent seeking allows each firm to capture a share of the "pie" and simultaneously increase the aggregate emissions cap.

\subsection{Rent seeking under a non-tradable rent}

To better understand the process of rent seeking for tradable permits, it is beneficial to consider, for a moment, the case where rents are not allowed to be ex post reallocated among firms. This benchmark represents the traditional command-and-control regulation for pollution rights, where firms are allocated the (non-tradable) right to pollute, such as performance-based standards (Freeman and Kolstad, 2008). To provide a meaningful comparison between rent seeking for ex post reallocated and standard (command-and-control) rents, we assume for the benchmark, that agents rent-seek for a non-tradable rent, denoted by $\tilde{A}$. It follows then that the payoff function for the firm is:

$$
a_{i}^{B}-v\left(s_{i}\right)
$$

where $a_{i}$ is the non-tradable benefit to firm $i$ determined by:

$$
a_{i}^{B}= \begin{cases}f\left(s_{i}, s_{-i}\right) \tilde{A} & \text { if } \sum_{i=1}^{n} s_{i}>0 \\ \frac{\tilde{A}}{n} & \text { otherwise }\end{cases}
$$

Given (10) and (11), the first order condition with respect to firm $i$ 's rent seeking effort $s_{i}$ is:

$$
f^{\prime}\left(s_{i}, s_{-i}\right) \tilde{A}-v^{\prime}\left(s_{i}\right)=0 \quad \text { for all } i=1,2, \ldots, n
$$

which is optimally solved for $s_{i}^{B}$, the optimal rent seeking effort when the rents are not tradable.

In the benchmark model, (12) shows that each firm will rent-seek so that their marginal

\footnotetext{
${ }^{5}$ Throughout the paper we use the interpretation of a divisible prize among agents. However, provided risk neutrality of the agents, a non-divisible rent, where there is a non-zero probability of winning, is functionally equivalent. Therefore, the alternative interpretation of this model is where agents participate in a contest for a single prize which can then be ex post reallocated after initial distribution.
} 
benefit is equal to the marginal cost.

\subsection{Equilibrium effort}

We now consider an alternative to this benchmark where the rent can be ex post reallocated and firms invest in rent seeking effort where each firm has the potential to not only influence their own allowance of permits but, from (1), the aggregate allocation. This means that the permit price is endogenously determined by the level of aggregate allocation and hence the level of aggregate rent seeking effort.

Firm $i$ now selects a level of rent seeking to maximise its payoff:

$$
\max _{s_{i}} p^{*}\left(a_{i}-e_{i}^{*}\left(A\left(s_{i}\right)\right)\right)-v\left(s_{i}\right)-c_{i}\left(e_{i}^{*}\left(A\left(s_{i}\right)\right)\right)
$$

where $e_{i}^{*}(A)$ is the equilibrium level of emissions chosen in stage three, $a_{i}$ is given by (8) and $v\left(s_{i}\right)$ is the (separable) cost of investing in rent seeking effort where $v^{\prime}\left(s_{i}\right), v^{\prime \prime}\left(s_{i}\right) \geq 0$ and $v(0)=0$. Differentiating (13) with respect to $s_{i}$ and noting from (3) that in the perfectly competitive market we have $\frac{\partial c_{i}}{\partial e_{i}}=p^{*}$ so that $p^{*} \frac{\partial e_{i}^{*}}{\partial s_{i}}=c_{i}^{\prime}\left(e_{i}\left(A\left(s_{i}\right)\right)\right)$ we obtain the following first order condition: ${ }^{6}$

$$
p^{*} \frac{\partial a_{i}}{\partial s_{i}}+\frac{\partial p^{*}}{\partial A} \frac{\partial A}{\partial s_{i}}\left(a_{i}-e_{i}^{*}\right)-v^{\prime}\left(s_{i}\right)=0 \quad \text { for all } i=1,2, \ldots, n
$$

where

$$
\frac{\partial a_{i}}{\partial s_{i}}=f^{\prime}\left(s_{i}, s_{-i}\right) A(s)+f\left(s_{i}, s_{-i}\right) A^{\prime}(s)
$$

To begin our discussion on rent seeking strategies under ex post reallocation, note that (14) illustrates two important marginal effects on firm $i$ 's rent seeking effort. The first term in (14) shows a positive marginal effect where a unilateral increase in firm $i$ 's rent seeking will increase its permit allocation and wealth, given the permit price $p^{*}$. From (15) one can see, from the first term, that this positive marginal influence is based on the marginal increase in firm $i$ 's share of permits (given a fixed allocation) and, from the second term, a marginal increase in permits from an increase in the aggregate cap (given a constant share of permits). The effect

\footnotetext{
${ }^{6}$ The second order conditions are satisfied for sufficiently small (absolute) values of $\frac{\partial^{2} p^{*}}{\partial A^{2}}$. We assume throughout that the second order conditions are satisfied at the optimal levels.
} 
of the second term in (14) is ambiguous and directly related to ex post reallocation. As will be discussed further below, when rent seeking increases this may increase the aggregate emissions cap which will reduce the equilibrium permit price. This is a positive marginal effect when the firm is an ex post net buyer of permits (i.e. $a_{i}-e_{i}^{*}<0$ ), as permits now become cheaper to purchase. However, if the firm is an ex post net seller of permits (i.e. $a_{i}-e_{i}^{*}>0$ ) this marginal effect is negative as the additional permits sold are now sold at a lower price. It follows from (14) that net buyers of permits tend to invest more in rent seeking than net sellers of permits. This result shows that allowing ex post reallocation in the form of a tradable permit market for rents creates a situation where equilibrium rent seeking effort is now dependent on equilibrium rents held. Comparing our model with the standard rent seeking benchmark, we are able to show the relative size of rent seeking effort in a tradable permit market:

Proposition 1 If $p^{*} A\left(s^{*}\right)>\tilde{A}$ then aggregate rent seeking for the endogenous rent is larger than the benchmark $\left(s^{*}>s^{B}\right)$. If $p^{*} A\left(s^{*}\right)<\tilde{A}$ then aggregate rent seeking for the endogenous rent is smaller (larger) than the benchmark for relatively small (large) levels of $p^{*} A^{\prime}\left(s^{*}\right)$.

\section{Proof. See Appendix A.}

Proposition 1 illustrates that when $p^{*} A\left(s^{*}\right)>A$ then the value of the rent to the firm under a tradable permit market is larger than the value of the rent under the benchmark and hence firms will invest relatively more in rent seeking effort. Note here that the implicit value of the allocation in the benchmark model has been normalised to one. It is clear that $A\left(s^{*}\right) \geq \tilde{A}$ as $A^{\prime}\left(s^{*}\right) \geq 0$ and $A(0)=\tilde{A}$, however, it is ambiguous whether the equilibrium price level, due to this increase supply of permits, is either larger or smaller than the normalised marginal benefit in the benchmark model. Let us now consider the case when $p^{*} A\left(s^{*}\right)<\tilde{A}$ where the value of the aggregate emissions cap is less than the value of the benchmark rent. In this case, the responsiveness of the equilibrium permit price plays a fundamental role in determining the relative size of rent seeking effort. From the appendix, the relative size of rent seeking is given by the term $\left[\tilde{A}-p^{*} A\left(s^{*}\right)\right] \sum_{i=1}^{n} f^{\prime}\left(s_{i}^{*}, s_{-i}^{*}\right)-p^{*} A^{\prime}\left(s^{*}\right)$ which shows that the relative size of rent seeking effort is ambiguous. One can see that as the difference between the different rent values $\tilde{A}-p^{*} A\left(s^{*}\right)$ increases then rent seeking effort will tend to decrease. This tends to occur more severely when the permit price is more responsive to changes in allocation. 


\subsection{An exogenous rent}

To see the incentive for firms to invest in rent seeking efforts more clearly, let us assume, for the moment, that the aggregate emissions cap is equal to the initial declared level (draft legislation), and not influenced by rent seeking. That is, the aggregate cap $A=\tilde{A}$ where $\mu=0$. Under such a scenario, the regulator's aggregate emissions are unresponsive to rent seeking, however, the distribution of rents among firms is still determined by rent seeking. With an equilibrium permit price $p^{* *}$, we can directly compare firms' rent seeking strategies from the exogenous rent $s_{i}^{* *}$ and the benchmark model.

Corollary 1 For an exogenously determined aggregate emissions cap, if (i) $p^{* *}<1$ then $s^{* *}<$ $s^{B}$ and (ii) $p^{* *}>1$ then $s^{* *}>s^{B}$ and the relative aggregate rent seeking effort is given by $\left[1-p^{* *}\right] \sum_{i=1}^{n} \frac{\partial a_{i}}{\partial s_{i}^{* *}}$.

\section{Proof. See Appendix A.}

This shows that as the marginal value of the ex post reallocated rent $\left(p^{* *}\right)$ is smaller than the marginal benefit from the benchmark (normalised to 1), then equilibrium rent seeking effort will be smaller than the benchmark case and vice versa. Additional to this, the aggregate marginal allocation from rent seeking $\sum_{i}^{n} \frac{\partial a_{i}}{\partial s_{i}^{* *}}$ augments the relative difference in rent seeking. This result is in line with standard rent seeking literature that explains that a larger value of rent will increase the amount of rent seeking. However, what is more interesting, and important to our model is the extent to which the price changes, as this determines the level of rent seeking activity. In order to view the consequences of a changing market value of rents we now turn to the analysis of aggregate rent seeking effort.

\subsection{Aggregate rent seeking effort}

From the viewpoint of the regulator, we only care about aggregate rent seeking and the effect it may have on the aggregate emissions cap and social welfare. Therefore, we first need to find the optimal rent seeking strategy for the entire market in stage two. To do this, we use a Tullock (1980) contest model (for surveys, see, for example, Nitzan, 1994; Konrad, 2009). Following convention, for risk neutral firms and constant returns to rent seeking, the initial allocation to 
firm $i$ in (8) is now transformed to:

$$
a_{i}=\left\{\begin{array}{ll}
\frac{s_{i}}{\sum_{i}^{n} s_{i}} A & \text { if } \sum_{i=1}^{n} s_{i}>0 \\
\frac{\tilde{A}}{n} & \text { otherwise }
\end{array} \quad \text { for all } i=1,2, \ldots, n\right.
$$

which shows that allocation to firm $i$ is based on their relative size of rent seeking efforts. That is, each firm's initial allocation is proportional to their investment in rent seeking effort.

Using the first order condition (14), summing over all $n$ first order conditions and noting the elimination of the second term due to the market clearing condition (4) assuming symmetric strategies in rent seeking $s=s_{i}=s_{-i}$, aggregate rent seeking is given by:

$$
S^{*}=p^{*} \frac{(n-1)}{n} \frac{\tilde{A}^{0}}{1-p^{*} \mu \tilde{A}^{0}}
$$

for $p^{*} \mu \tilde{A}^{0}<1$ where the marginal increase in value of the ex post reallocated rent $p^{*} \mu \tilde{A}^{0}$ is lower than the marginal cost of rent seeking, otherwise agents would choose the maximum possible level of resource-seeking. Applying (16) to the benchmark model in (11) yields the familiar aggregate rent seeking strategy $S^{B *}=\frac{(n-1)}{n} \tilde{A}^{0}$. The major distinction between this and our ex post reallocation rent seeking strategy is that our model now includes the equilibrium permit price as the market value for the ex post reallocation rent. Comparative statics of the aggregate equilibrium rent seeking strategy, yields:

$$
\begin{aligned}
\frac{\partial S^{*}}{\partial p^{*}} & =\frac{(n-1)}{n} \frac{\tilde{A}^{0}}{\left(1-p^{*} \mu \tilde{A}^{0}\right)^{2}}>0 \\
\frac{\partial S^{*}}{\partial \mu} & =\Psi \frac{(n-1)}{n} \frac{\tilde{A}^{0}}{\left(1-p^{*} \mu \tilde{A}^{0}\right)^{2}}
\end{aligned}
$$

where

$$
\Psi=\left[\frac{\partial p^{*}}{\partial A} \frac{\partial A}{\partial \mu}+\tilde{A}^{0}\left(p^{*}\right)^{2}\right]
$$

As suggested above, and now shown in equation (18), an (exogenous) increase in the equilibrium permit price will increase aggregate rent seeking effort, as the ex post reallocated rents increase in value. 
Let us consider the response to a regulator's exogenously changing responsiveness $\mu$ in (19). From $\Psi$ there are two effects on marginal rent seeking. First, from (1) and (7) we define the Price Effect as $\frac{\partial p}{\partial A} \frac{\partial A}{\partial \mu}$ so that as the regulator's responsiveness increases, this may increase the number of permits which has the potential to reduce the equilibrium price experienced and decrease rent seeking effort. In the analysis of standard rents, this effect does not exist. The second component $\tilde{A}^{0} p^{2}>0$ we denote as the Wealth Effect where, if the regulator's responsiveness increases then rent-seekers have a larger number of permits and increased wealth. Therefore, when $\Psi>0$, the wealth effect dominates the price effect and marginal rent seeking effort is positive $\left(\frac{\partial S^{*}}{\partial \mu}>0\right)$ whereas when $\Psi<0$ the price effect dominates the wealth effect which results in negative marginal rent seeking activity $\left(\frac{\partial S^{*}}{\partial \mu}<0\right)$.

Differentiating the aggregate rent seeking strategy (17) with respect to the regulator's optimal allocation choice, reveals, after some manipulation:

$$
\frac{\partial S^{*}}{\partial \tilde{A}^{0}}=\frac{(n-1)}{n} p^{*} \frac{\left[1+\varepsilon_{p}\right]}{\left(1-p^{*} \mu \tilde{A}^{0}\right)^{2}}
$$

where $\varepsilon_{p}=\frac{\partial p^{*}}{\partial \tilde{A}^{0}} \frac{\tilde{A}^{0}}{p^{*}}$ is the elasticity of the equilibrium price level based on a change in the regulator's aggregate allocation choice. ${ }^{7}$ From $(20)$, note that we can again see the difference between ex post reallocated rents and standard rents. In standard rents, $\frac{\partial S^{*}}{\partial \tilde{A}^{0}}$ is always positive as the increase in rent increases wealth. However, from (20), we see that the size of $\varepsilon_{p}$ will determine whether $\frac{\partial S^{*}}{\partial \tilde{A}^{0}}$ is positive or negative. Importantly, we find increasing the size of the rent (here, the total supply of permits) has an ambiguous effect on rent seeking. This is in direct contrast to frameworks that investigate standard rents (Shaffer, 2006).

To compare aggregate rent seeking effort under exogenous and endogenous cases note aggregate rent seeking for an exogenously determined rent is:

$$
S^{* *}=p^{* *} \frac{(n-1)}{n} \tilde{A}^{0}
$$

where the superscript ${ }^{* *}$ denotes the exogenous case. Therefore, comparing (17) and (21), the relative difference in aggregate rent seeking efforts between exogenous and endogenous

\footnotetext{
${ }^{7}$ Note this is the inverse of a standard price elasticity of demand.
} 
determined ex post reallocated rents is given by:

$$
\frac{S^{*}}{S^{* *}}=\frac{p^{*}}{p^{* *}} \frac{1}{1-p^{*} \mu \tilde{A}^{0}}
$$

Expression (22) shows that the relative difference between rents that are exogenous and endogenously determined is based on the two effects discussed above. Firstly, we know that $\frac{p^{*}}{p^{* *}} \leq 1$ as, by definition, the aggregate cap chosen in the endogenous case must be at least the size of the exogenous cap. Therefore from (7), the permit price must be relatively smaller which results in greater pressure for rent seeking effort in the case of the exogenously determined cap. Second, $\frac{1}{1-p^{*} \mu \tilde{A}^{0}} \geq 1$ which increases rent seeking for the endogenously determined rent as more permits are allowed which provide additional wealth. To what extent rent seeking efforts are larger in exogenous or endogenously determined aggregate emissions caps therefore depends on the relative size of these two effects.

\section{Stage one: regulator's optimal choice of aggregate emis- sions}

In stage one, the regulator will select a level of aggregate emissions $\tilde{A}^{*}$. As a consequence the resulting aggregate emissions level will be determined by expression (1) so that $A^{*}=$

$\tilde{A}^{*}\left(1+\mu \sum_{i=1}^{n} s_{i}^{*}\right)$ where $\sum_{i=1}^{n} s_{i}^{*}$ are the aggregate rent seeking efforts from stage two. Let us initially assume that the regulator, such as the US EPA, is solely concerned about maximising social welfare in that region. We return to the case where the regulator is concerned about the attainment of political contributions at the end of this section.

\subsection{The regulator's optimal choice of aggregate emissions}

The regulator's aim is to maximise the net welfare $W$ which consists of firms' net profits from the tradable permit market $\sum_{i=1}^{n} \Pi_{i}(A)$ minus the damage from the emissions and the cost of the (socially unproductive) rent seeking effort. More formally, the regulator's objective function is:

$$
\max _{\tilde{A}} W=\sum_{i=1}^{n} \Pi_{i}(A)-D(A)-V^{*}(A)
$$


where $D(A)$ is the damage caused by emissions where $D^{\prime}(A), D^{\prime \prime}(A) \geq 0$ and $V^{*}(A)=\sum_{i=1}^{n} v\left(s_{i}^{*}\right)$ is the aggregate rent seeking cost from all firms participating in the tradable permit market.

Using backward induction, the regulator knows equilibrium rent seeking effort by observing (17) that occurs in stage two according to a given level of $\mu$ and $A$. In order to show the regulator's optimal choice of allocation, it is important to compare this result to the socially optimal case when there exists no rent seeking effort. That is, what aggregate allocation level would the regulator choose under the presence of zero rent seeking? As shown in Appendix B, when zero rent seeking occurs the regulator selects an aggregate emissions cap so that:

$$
p^{*}=\frac{\partial D(A)}{\partial A}
$$

which is optimally solved for $\tilde{A}^{B}$ (here we have $\frac{\partial A}{\partial \tilde{A}}=1$ hence $\frac{\partial D(A)}{\partial A}=\frac{\partial D(A)}{\partial \tilde{A}}$ ). This states that the regulator should set a level of aggregate emissions so that the marginal benefit (the equilibrium permit price) is equated to the marginal damage of emissions.

In order to solve for the regulator's optimal aggregate allocation in (23), we first sum over all firms' profit functions which gives $-\sum_{i=1}^{n} c_{i}\left(e_{i}\right)$ and differentiating with respect to $\tilde{A}$ yields:

$$
-\sum_{i=1}^{n} \frac{\partial c_{i}}{\partial e} \frac{\partial e^{*}}{\partial A} \frac{\partial A}{\partial \tilde{A}}
$$

and using (3), this simplifies to:

$$
p^{*} \frac{\partial A}{\partial \tilde{A}} \sum_{i=1}^{n} \frac{\partial e_{i}^{*}}{\partial A}
$$

and noting that $\frac{\partial e^{*}}{\partial A}=1$ this reduces to: ${ }^{8}$

$$
\frac{\partial}{\partial \tilde{A}}\left(\sum_{i=1}^{n} \Pi_{i}(A)\right)=p^{*} \frac{\partial A}{\partial \tilde{A}}
$$

Given that firms are risk neutral, it follows that $V^{*}(A)=\sum_{i=1}^{n} v\left(s_{i}^{*}\right)=\sum_{i=1}^{n} s_{i}^{*}=S^{*}$ can be substituted into (23). Differentiating (23) with respect to $\tilde{A}$ and substituting in (27) yields 1

${ }^{8}$ Note that $\sum_{i=1}^{n} \frac{\partial e_{i}^{*}}{\partial A}=\sum_{i=1}^{n}\left[\frac{1}{\sum_{j=1}^{n} \frac{c_{i}^{\prime \prime \prime}\left(e_{i}\right)}{c_{j}^{\prime \prime}\left(e_{j}\right)}}\right]=\sum_{i=1}^{n}\left[\frac{1}{c_{i}^{\prime \prime}\left(e_{i}\right)} \frac{1}{\sum_{j=1}^{n}\left(\frac{1}{c_{j}^{\prime \prime \prime}\left(e_{j}\right)}\right)}\right]=\frac{1}{\sum_{j=1}^{n}\left(\frac{1}{c_{j}^{\prime \prime}\left(e_{j}\right)}\right)} \cdot \sum_{i=1}^{n}\left(\frac{1}{c_{i}^{\prime \prime}\left(e_{i}\right)}\right)=$ 
the regulator's first order condition: ${ }^{9}$

$$
p^{*} \frac{\partial A}{\partial \tilde{A}}-\frac{\partial S^{*}}{\partial A} \frac{\partial A}{\partial \tilde{A}}-D^{\prime}(A) \frac{\partial A}{\partial \tilde{A}}=0
$$

Therefore $\tilde{A}^{*}$ is chosen so that (28) holds. Note there are three influences on the regulator's optimal choice of allocation. First there is an upward influence in the form of marginal increase in firms' profit due to the increased aggregate allocation $p^{*} \frac{\partial A}{\partial \tilde{A}}$. Further, $\frac{\partial S^{*}}{\partial A} \frac{\partial A}{\partial \tilde{A}}$ which is shown in (20) has an ambiguous influence in terms of the marginal change in optimal aggregate rent seeking effort and finally a downward influence due to the additional damage produced. Furthermore, we obtain an expression that allows analysis of the aggregate emissions level chosen by the regulator:

Lemma 1 In the presence of rent seeking effort, the regulator's optimal choice of aggregate allocation $\tilde{A}^{*}$ is chosen so that:

$$
p^{*} \Delta=\frac{\partial D(A)}{\partial A}
$$

where $\Delta=\left[1-\frac{(n-1)}{n} \frac{\left[1+\varepsilon_{p}\right]}{\left(1+\mu S^{*}\left(1+\frac{\left[1+\varepsilon_{p}\right]}{\left(1-p^{*} \mu \tilde{A}\right)}\right)\right)\left(1-p^{*} \mu \tilde{A}\right)^{2}}\right]$.

Proof. See Appendix C.

Direct comparison of (24) and (29) shows that the regulator's choice of aggregate emissions cap is only socially optimal when $\Delta=1$, that is $\left|\varepsilon_{p}\right|=1$, where the responsiveness of the permit price is unitary to changes in the regulator's choice of allocation. When $\left|\varepsilon_{p}\right|<1$, the price is relatively insensitive which results in a relatively stable permit price and hence a stable level of aggregate rent seeking. As a result, aggregate emissions tend to be smaller than socially optimal as the regulator takes this into account and reduces the amount of permits available. For $\left|\varepsilon_{p}\right|>1$, we have to consider the sign of $\left(1+\mu S^{*}\left(1+\frac{\left[1+\varepsilon_{p}\right]}{\left(1-p^{*} \mu \tilde{A}\right)}\right)\right)$. In particular, this can be rearranged so that we define $\left|\bar{\varepsilon}_{p}\right|$ as the value of elasticity that solves:

$$
\left[1+\varepsilon_{p}\right]=-\frac{\left(1-p^{*} \mu \tilde{A}^{0}\right)}{(n-1) p^{*} \mu \tilde{A}^{0}}\left[n-p^{*} \mu \tilde{A}^{0}\right]<0
$$

When $1<\left|\varepsilon_{p}\right|<\left|\bar{\varepsilon}_{p}\right|$ then we find the regulator selects a level of aggregate emissions above the socially optimal level. As the price is very responsive, aggregate emissions are above

\footnotetext{
${ }^{9}$ The second order conditions are satisfied for the optimal value given a sufficiently small (absolute) $\frac{\partial^{2} S^{*}}{\partial A^{2}}$.
} 
the socially optimal level because rent seeking effort falls improving welfare which allows the regulator to allocate more permits to the firms. Counter-intuitively, it is not the actual rent seeking that increases the aggregate emissions but the reduction in social costs associated with a reduction in rent seeking that allows the regulator to issue additional permits. For completeness, we also have the case where $\left|\varepsilon_{p}\right|>\left|\bar{\varepsilon}_{p}\right|$. In this case, the price is extremely sensitive, so much so that, the regulator's optimal choice of aggregate emissions is chosen below the socially optimal level.

As the regulator understands that "unavoidable responsiveness" may exist, in that its draft legislation may indeed increase in aggregate size throughout the political process, the regulator combats this by using its first mover advantage and adjusting the initial aggregate allocation $\tilde{A}$ accordingly. Therefore, a lower initial aggregate allocation (than socially optimal) will be chosen when it is anticipated that a significant amount of rent seeking will occur in stage two and vice versa (which can be determined by analysing the responsiveness of the equilibrium permit price).

\subsection{Regulatory responsiveness and welfare}

From above, we were able to show that the regulator's optimal choice of allocation depends on how responsive the equilibrium permit price is to changing allocations. Another type of responsiveness is that of the regulator towards the setting of the initial allocation. Can a change in regulatory responsiveness (i.e. a change in rent seeking culture) change welfare? That is, given the optimal regulator's decision determined in (29), how does changing the responsiveness parameter $\mu$ alter welfare for society?

By solving for $\frac{d W}{d \mu}$ we can show how the regulator's responsiveness alters welfare.

Lemma 2 The welfare change given by an increase in the regulator's responsiveness is:

$$
\frac{d W}{d \mu}=\left[p^{*}-D^{\prime}\left(A^{*}\right)\right] \frac{\partial A^{*}}{\partial \mu}-\frac{\partial S^{*}}{\partial \mu}
$$

\section{Proof. See Appendix C.}

From Lemma 2, two main factors determine whether increasing responsiveness changes welfare. The first term $\left[p^{*}-D^{\prime}\left(A^{*}\right)\right] \frac{\partial A^{*}}{\partial \mu}$ shows the distance away from the socially optimally 
chosen level of allocation which is derived in Lemma 1. Under a socially optimal emissions cap, expression (24) shows that $p^{*}-D^{\prime}\left(A^{*}\right)=0$. However, Lemma 1 shows that, in most cases this tends to be non-zero. In fact when $p^{*}-D^{\prime}\left(A^{*}\right)<0$ emissions are larger than socially optimal and smaller when $p^{*}-D^{\prime}\left(A^{*}\right)>0$. Second, the marginal change in rent seeking alters welfare.

Everything else constant, Lemma 2 shows that a reduction in rent seeking unambiguously improves welfare. This is not surprising as rent seeking is a socially unproductive activity. For $\frac{\partial S^{*}}{\partial \mu}<0$ to hold, it follows from (19) that $\Psi<0$ which implies the price effect is larger than the wealth effect. This requires the price change, due to a change in responsiveness and hence the aggregate allocation, to be relatively elastic. As discussed above, if the equilibrium permit price is relatively elastic, a change in the aggregate allocation of permits will reduce the price (value) of the permits substantially and firms will have an incentive to reduce rent seeking effort.

Now let us consider the difference in optimally chosen aggregate emissions when $\Psi<0$. It is easy to show in these conditions that the equilibrium permit is relatively elastic $\left|\varepsilon_{p}\right|>1$ and using Lemma 1 it possible that $p^{*}-D^{\prime}\left(A^{*}\right)<0$ which has a negative effect on welfare. From Lemma 2 it is clear that the optimally chosen emissions and the change in rent seeking activity may work in opposite directions. For instance, when a reduction in rent seeking occurs, emissions tend to be pushed above the socially optimal level. From Lemma 2 it is unclear as to the net effect on welfare given a change in responsiveness. The effects of an increase in regulatory responsiveness on welfare is given by the following Proposition:

Proposition 2 For an exogenous increase in regulatory responsiveness $\mu$, (i) welfare decreases when $\left|\varepsilon_{p}\right|<1$ and $\left|\varepsilon_{p}\right|<\left|\hat{\varepsilon}_{p}\right|$ (ii) welfare increases for $\left|\varepsilon_{p}\right|>\left|\hat{\varepsilon}_{p}\right|$ where $\left|\hat{\varepsilon}_{p}\right|$ solves the equality:

$$
\frac{(n-1)}{n}=\frac{\left(1-p^{*} \mu \tilde{A}^{*}\right)^{2}}{\left(1-p^{*} \mu \tilde{A}^{*}\right)^{2}-p^{*} \mu \tilde{A}^{*}\left[1+\varepsilon_{p}\right]}
$$

Proof. See Appendix D.

Proposition 2 shows that given the balance between the distortion in aggregate emissions and marginal rent seeking observed in Lemma 2, an increase in the regulatory responsiveness will unambiguously decrease welfare when $\left|\varepsilon_{p}\right|<\left|\hat{\varepsilon}_{p}\right|$ and $\left|\varepsilon_{p}\right|<1$. That is, the increase in the emissions (away from the socially optimal level) will be greater than the improvement caused by a reduction in rent seeking effort. We find that as the number of firms participating in rent 
seeking increases, the decrease in welfare will become smaller. Intuitively, when more firms rent seek there is a larger social loss created by that rent seeking. Therefore when regulatory responsiveness increases, the change in aggregate rent seeking is larger and net welfare decreases by less.

However, when the price is sufficiently elastic, $\left|\varepsilon_{p}\right|>\left|\hat{\varepsilon}_{p}\right|$, then it is possible for social welfare to increase as the reduction in socially wasteful rent seeking outweighs the increase in damages from aggregate emissions.

\subsection{The regulator and political contributions}

Up to this point, we have considered a regulator that acts benevolently by selecting a level of aggregate emissions to maximise social welfare where it views rent seeking as socially wasteful. However, it is clear that regulators (politicians) may obtain a benefit in the form of political contributions which may alter the incentives to select the level of aggregate emissions (Grossman and Helpman, 1994). In this subsection, we extend our model by allowing the regulator to optimise the standard social welfare function with the additional (weighted) political contribution benefits.

To show this, let us assume that the regulator obtains political contributions from rent seekers given by $\beta S^{*}$ where $\beta>0$ is an exogenous parameter representing the weight to which the regulator can attain political contributions from rent seekers. From the regulator's payoff function in (23) we know that the net gain from rent seeking is given by $-(1-\beta) S^{*}$. When $0<$ $\beta<1$ the net benefit from the political contributions is negative and similar (but augmented) results are found to the case when the regulator attains no political contributions. However when $\beta>1$ the net benefits of attaining political contributions are positive and additional results exist. In particular, the regulator's choice of emissions is now determined by

$$
p^{*}\left[1+(\beta-1) \frac{(n-1)}{n} \frac{\left[1+\varepsilon_{p}\right]}{\left(1+\mu S^{*}\left(1+\frac{\left[1+\varepsilon_{p}\right]}{\left(1-p^{*} \mu \tilde{A}\right)}\right)\right)\left(1-p^{*} \mu \tilde{A}\right)^{2}}\right]=D^{\prime}(A)
$$

Let us assume that $\beta<\bar{\beta}$ where $\bar{\beta}$ is the maximum level in which the left hand side is positive. It follows that: 
Corollary 2 For, $1<\beta<\bar{\beta}$, (i) When $\left|\varepsilon_{p}\right|<1$ or $\left|\bar{\varepsilon}_{p}\right|<\left|\varepsilon_{p}\right|$ then $p^{*}-D^{\prime}(A)<0$ and emissions are higher than optimal (ii) If $\left|\bar{\varepsilon}_{p}\right|>\left|\varepsilon_{p}\right|>1$ then $p^{*}-D^{\prime}(A)>0$ and emissions are lower than optimal

\section{Proof. See Appendix D.}

In contrast to the previous case, Corollary 2 now shows that the regulator has an incentive to increase emissions when the elasticity $\varepsilon_{p}$ (given a change in the allocation) is inelastic $\left|\varepsilon_{p}\right|<1$. Intuitively, as the price is unresponsive, an increase in emissions results in only a small decrease in price and consequently rent seeking effort continues to be relatively large which produces a large amount of political contributions for the regulator. Similar logic applies when $\left|\bar{\varepsilon}_{p}\right|>$ $\left|\varepsilon_{p}\right|>1$ and an incentive exists to reduce the aggregate level of emissions. For the extreme case where $\left|\varepsilon_{p}\right|>\left|\bar{\varepsilon}_{p}\right|$ the regulator selects a level of emissions above the socially optimal level.

We can also consider the effect on the regulator's payoff when there is a change in the exogenous parameter $\mu$. Unlike the case where there are no political contributions, we find:

Proposition 3 Given the regulator receives political contributions where $1<\beta<\bar{\beta}$ then the regulator's payoff (i) increases when $\left|\varepsilon_{p}\right|<1$ and $\left|\varepsilon_{p}\right|<\left|\hat{\varepsilon}_{p}\right|$, (ii) welfare decrease for $\left|\varepsilon_{p}\right|>\left|\hat{\varepsilon}_{p}\right|$ where $\left|\hat{\varepsilon}_{p}\right|$ is a threshold elasticity value.

\section{Proof. See Appendix D.}

Under a regime in which regulators are responsive, we find that an increase in the responsiveness to rent seekers, in terms of changing social norms and so on, will usually result in the regulator's payoff increasing. Here the benefits obtained from the political contributions outweigh the increase in damages. Similarly, the elasticity could be so high that political contributions fall significantly so that the regulator's payoff decreases.

\section{Discussion}

The incentive to rent seek for tradable pollution permit differs from traditional rents in that the market for permits produces an equilibrium permit price which influences the rent seeking incentives of firms and the selection of aggregate emissions by the regulator. This is clearly seen when one considers a regime where regulatory responsiveness exists. The responsiveness of the regulator can be viewed as a stabilisation or deterrent against "excessive" rent seeking. 
If rent seeking increases this has a knock-on-effect on the aggregate supply to the market and as a result reduces the value of permits. However, even if rent seeking is stablised under a tradable permit market, allowing regulatory responsiveness is usually welfare decreasing.

From (7) we can see that the change in the equilibrium permit price is based on the slopes of firms' marginal abatement cost functions. That is, relatively steeper marginal abatement costs functions (i.e. each additional unit of abatement is relatively more expensive), result in a more responsive equilibrium permit price. Therefore, it follows that in markets where firms' marginal abatement cost functions are steep and rent seeking is a significant and costly problem, a regulator will decrease welfare when regulatory responsiveness exists. ${ }^{10}$ Considering current tradable permit markets, permit prices do seem to be relatively responsive to market conditions. For example, EU-ETS allowance prices have had significant volatility since their inception. The most noticeable change occurred in April-May 2006 with a significant drop in equilibrium permit prices due to additional information being released regarding Member States' over-allocation of emissions (Ellerman et al., 2007).

To the extent that different political regimes allow differing regulatory responsiveness, it is clear that for welfare to improve, the regulatory responsiveness should be low as possible in determining the aggregate emissions (for inelastic and elastic prices up to a threshold level). Ideally, the ex-ante creation of market rules should help restrict the possible consequences of rent seeking, yet this may prove hard to implement as it may be hard to identify whether firm actions are firm/industry participation in creating realistic targets or simply rent seeking for additional permits and aggregate emissions. An important distinction exists between allowing the firms to determine the aggregate emissions cap through rent seeking and the recent arguments for allowing flexible absolute emissions caps. These ideas suggest introducing energy intensity targets instead of absolute emission targets to help maintain growth levels in economies and reduce uncertainty (Fischer, 2003; Kolstad, 2005; Pizer, 2005) or even using "reserves" or "safety valves" to reduce price volatility and improve the cost effectiveness of tradable permit markets (Pizer, 1999; 2002; Jacoby and Ellerman, 2004; Newell et al., 2005).

\footnotetext{
${ }^{10}$ Steep marginal abatement cost may actually cause significant amounts of rent-seeking as these firms tend to find investment in abatement relatively expensive and are more likely to consider invest in rent-seeking as an alternative.
} 


\section{Conclusion}

A contentious and demanding aspect of a regulator's role in a tradable permit market is the initial allocation of permits. In particular, the determination of the aggregate emissions cap and the distribution of permits among participants remain controversial issues. Like most valuable rents, a significant amount of rent seeking effort tends to be employed to influence both the size and the distribution of the rent. Yet in contrast to traditional contestable rents, tradable rents, such as tradable pollution permits, allow for ex post reallocation. Therefore, it is important to understand how this alters agents' incentives to rent seek.

We introduce a contest where polluting firms in a tradable permit market have the option to invest in rent seeking effort that has the potential to increase (i) their own permit allocation within the tradable permit market and (ii) the aggregate supply of permits from the regulator (i.e. political pressure to increase the aggregate level of emissions). The regulator selects a provisional aggregate emissions target but this can be influenced by firms' rent seeking effort. We analyse two cases where the regulator views rent seeking as 'purely' socially wasteful and where the regulator obtains political contributions from rent seekers. We show the incentives behind firms' rent seeking effort in a tradable permit market and compare this to a standard rent seeking framework. We find individual rent seeking strategies depend on whether, in equilibrium, the firm is a net buyer or seller of the ex post reallocated rent (initial allocation of permits).

In a tradable permit market, a regulator must understand the effects of rent seeking on the equilibrium permit price (and thus the value of the ex post reallocated rent) and the social loss created by rent seeking. This paper shows that, although the equilibrium permit price effect has the potential to reduce socially wasteful rent seeking effort, it cannot usually improve net welfare when the regulator's responsiveness to aggregate rent seeking increases.

Using this model allows direct comparison between standard and ex post reallocated rents, such as tradable pollution permits. Importantly, it is this ability of firms to bargain the ex post reallocated rents that defines the incentives to rent-seek. Allowing ex post reallocation creates a price effect that influences the equilibrium levels of rent seeking not seen in the traditional contestable rents story. As the market value of the rent is linked to the supply of permits, when a regulator is responsive to rent seeking this then acts as a type of stabilisation or deterrent 
against rent seeking as any increase in rent seeking will result in a reduction in the value of the rent.

\section{Acknowledgements}

The authors would like to thank Gordon Brady, Ian Lange and seminar participants at the University of Stirling and SES 2009 for useful comments and suggestions. The usual disclaimer applies.

\section{References}

Chung T-Y., 1996. Rent seeking contest when the prize increases with aggregate efforts. Public Choice, 87, 55-66.

Dari-Mattiacci, G., Opstal, S., Parisi, F., 2009. Seeking rent in the shadow of Coase. Public choice, forthcoming.

Fischer, C., 2003. Combining rate-based and cap-and-trade emissions policies. Climate Policy, (S2), S89-S103.

Ellerman, A. D., Joskow, P. L., Schmalensee, R, Montero, J-P., Bailey, E. M. 2000. Markets for clear air: The U.S. Acid Rain Program. Centre for Energy and Environmental Policy Research, Massachusetts Institute of Technology, Cambridge University Press.

Ellerman, A. D., Buchner, B. K., Carraro, C. (Eds.), 2007. Allocation in the European emissions trading scheme: rights, rents and fairness. Cambridge University Press, Cambridge.

Freeman, J., Kolstad, C., (Eds.), 2007. Moving to Markets: lessons from Twenty Years of Experience. Oxford University Press, New York.

Grossman, G.M., Helpman, E., 1994. Protection for sale. American Economic Review, 84 (4), 833-850.

Helm, C., 2003. International emissions trading with endogenous allowance choices. Journal of Public Economics, 87(12), 2737-2747. 
Jacoby, H.J., Ellerman, A. D., 2004. The safety valve and climate policy. Energy Policy, 32(4) 481-491.

Kolstad C.D., 2005. Climate change policy from the USA. in Hansjugens, B. (Ed.) 'Emissions Trading for Climate Policy: US and European Perspectives', Cambridge University Press, Cambridge pp 96-113.

Konrad, K.A., 2009. Strategy and dynamics in contests. Oxford University Press, Oxford.

Krishna, V., 2002. Auction theory. Elsevier, London, UK

Krueger, A. O., 1974. The political economy of the rent seeking society. American Economic Review, 64, 291-303.

Lai, Y-B., 2007. The optimal distribution of pollution rights in the presence of political distortions. Environmental and Resource Economics, 36 (3), 367-388.

Montgomery, D., 1972. Markets in licenses and efficient pollution control programs. Journal of Economic Theory, 5 (3), 395-418.

Newell, R.G., Pizer, W.A., Zhang, J., 2005. Managing permit markets to stabilize prices. Environmental and Resource Economics, 31 (2) 133-157.

Nitzan, S., 1994. Modelling rent seeking contests. European Journal of Political Economy, 10 , 41-60.

Pizer, W.A., 1999. The optimal choice of climate change policy in the presence of uncertainty. Resource and Energy Economics, 21 (3-4) 255-287.

Pizer, W.A., 2002. Combining price and quantity controls to mitigate global climate change. Journal of Public Economics, 85 (3), p. 409-434.

Pizer, W.A., 2005. The case for intensity targets. Climate Policy, 5 (4), 455-462.

Posner, R., 1975. The social costs of monopoly and regulation. Journal of Political Economy, $83,807-827$.

Point Carbon, 2009. Carbon market North America. 4 (16). $24^{\text {th }}$ April 2009. http://www.pointcarbon.com/news/cmna/1.1104026 
Shaffer, S., 2006. War, labor tournaments and contest payoffs. Economics Letters, 92, 250-255.

Skaperdas, S., 1996. Contest success functions. Economic Theory 7, 283-290.

Sui, Y., 2009. Rent seeking contests with private values and resale. Public Choice, 138, 409-422.

Svendsen, G., 2005. Lobbyism and $\mathrm{CO}_{2}$ trade in the EU. in Hansjugens, B (ed) 'Emissions Trading for Climate Policy: US and European Perspectives', Cambridge University Press, Cambridge pp150-161.

Tullock, G., 1980. Efficient rent seeking. in Buchanan, J M, Tolison, R D and Tullock, G (eds), Towards a theory of the rent seeking society. Texas A\&M University Press.

\section{Appendix A}

\section{Proof of Proposition 1:}

Proof. The first order condition, with respect to rent seeking effort, is:

$$
\begin{aligned}
0= & \frac{\partial p}{\partial A} A^{\prime}\left(s^{*}\right)\left(f\left(s_{i}^{*}, s_{-i}^{*}\right) A\left(s^{*}\right)-e_{i}\right)+ \\
& +p^{*}()\left[f^{\prime}\left(s_{i}^{*}, s_{-i}^{*}\right) A\left(s^{*}\right)+f\left(s_{i}^{*}, s_{-i}^{*}\right) A^{\prime}\left(s^{*}\right)\right]-v^{\prime}\left(s_{i}^{*}\right)
\end{aligned}
$$

which is solved for firm $i$ 's rent seeking strategy $s_{i}^{*}$. Substituting this level of rent seeking into the benchmark first order condition we obtain:

$$
0 \neq f^{\prime}\left(s_{i}^{*}, s_{-i}^{*}\right) \tilde{A}-v^{\prime}\left(s_{i}^{*}\right)
$$

substituting (A1) into (A2), yields:

$$
\begin{gathered}
f^{\prime}\left(s_{i}^{*}, s_{-i}^{*}\right) \tilde{A}-\left[\begin{array}{c}
\frac{\partial p^{*}}{\partial A} A^{\prime}\left(s^{*}\right)\left(f\left(s_{i}^{*}, s_{-i}^{*}\right) A\left(s^{*}\right)-e_{i}\right)+ \\
+p^{*}()\left[f^{\prime}\left(s_{i}^{*}, s_{-i}^{*}\right) A\left(s^{*}\right)+f\left(s_{i}^{*}, s_{-i}^{*}\right) A^{\prime}\left(s^{*}\right)\right]
\end{array}\right] \neq 0 \\
{\left[\tilde{A}-p^{*} A\left(s^{*}\right)\right] f^{\prime}\left(s_{i}^{*}, s_{-i}^{*}\right)-\left[\frac{\partial p^{*}}{\partial A}\left(a^{*}-e_{i}\right)+p^{*}() f\left(s_{i}^{*}, s_{-i}^{*}\right)\right] A^{\prime}\left(s^{*}\right) \neq 0}
\end{gathered}
$$


summing up over the $n$ first order conditions, we obtain:

$$
\begin{aligned}
& \sum_{i=1}^{n}\left[A-p^{*} A\left(s^{*}\right)\right] f^{\prime}\left(s_{i}^{*}, s_{-i}^{*}\right)-p^{*} \sum_{i=1}^{n} f\left(s_{i}^{*}, s_{-i}^{*}\right) A^{\prime}\left(s^{*}\right) \\
& {\left[\tilde{A}-p^{*} A\left(s^{*}\right)\right] \sum_{i=1}^{n} f^{\prime}\left(s_{i}^{*}, s_{-i}^{*}\right)-p^{*} A^{\prime}\left(s^{*}\right) \sum_{i=1}^{n} f\left(s_{i}^{*}, s_{-i}^{*}\right)}
\end{aligned}
$$

Note that from (9), $\sum_{i}^{n} f\left(s_{i}^{*}, s_{-i}^{*}\right)=1$ which gives:

$$
\left[\tilde{A}-p^{*} A\left(s^{*}\right)\right] \sum_{i=1}^{n} f^{\prime}\left(s_{i}^{*}, s_{-i}^{*}\right)-p^{*} A^{\prime}\left(s^{*}\right)
$$

As $A^{\prime}\left(s^{*}\right)>0$, it follows that when $\tilde{A}-p^{*} A\left(s^{*}\right)<0$ then $\left[\tilde{A}-p^{*} A\left(s^{*}\right)\right] \sum_{i=1}^{n} f^{\prime}\left(s_{i}^{*}, s_{-i}^{*}\right)-$ $p^{*} A^{\prime}\left(s^{*}\right)<0$ and due to the concavity of $f($.$) and convexity of v($.$) , it follows that s^{*}>s^{B}$. When $\tilde{A}-p^{*} A\left(s^{*}\right)>0$, then the opposite result can be found as long as $p^{*} A^{\prime}\left(s^{*}\right)$ is sufficiently small so that $\left[\tilde{A}-p^{*} A\left(s^{*}\right)\right] \sum_{i}^{n} f^{\prime}\left(s_{i}^{*}, s_{-i}^{*}\right)-p^{*} A^{\prime}\left(s^{*}\right)>0$. In such a case $s^{*}<s^{B}$.

\section{Proof of Corollary 1:}

Proof. Substituting $A=\tilde{A}$ into the proof of Proposition 1 and noting that $A^{\prime}\left(s^{*}\right)=0$ we find

$$
\left[1-p^{* *}\right] \sum_{i=1}^{n} f^{\prime}\left(s_{i}^{* *}, s_{-i}^{* *}\right) \tilde{A} \neq 0
$$

hence if $p^{* *}>1$ then $s^{* *}>s^{B}$ and if $p^{* *}<1$ then $s^{* *}<s^{B}$. Summing up over all firms we obtain the total difference between rent seeking effort between the benchmark model and the exogenously determined emissions cap:

$$
\sum_{i=1}^{n}\left[1-p^{* *}\right] f^{\prime}\left(s_{i}^{* *}, s_{-i}^{* *}\right) \tilde{A}=\left[1-p^{* *}\right] \sum_{i=1}^{n} \frac{\partial a_{i}}{\partial s_{i}^{* *}} \neq 0
$$

\section{Appendix B}

Proof of derivation for regulator's benchmark case: 
Proof. For zero rent seeking activity, firm $i$ objective function is:

$$
\Pi_{i}=p^{*}\left(a_{i}^{*}-e_{i}^{*}\right)-c_{i}\left(e_{i}^{*}\right)
$$

for optimal choices $\left(e_{i}^{*}, a_{i}^{*}\right)$. So the social welfare function is:

$$
\max _{\tilde{A}} W=\sum_{i=1}^{n} \Pi_{i}-D(A)
$$

We also know that $a_{i}^{*}=A / N=\tilde{A} / N$ and $\frac{\partial A}{\partial \tilde{A}}=1$. The first order condition is:

$$
\frac{\partial \Pi_{i}}{\partial \tilde{A}}=\frac{\partial p^{*}}{\partial \tilde{A}}\left(a_{i}^{*}-e_{i}^{*}\right)+p^{*}\left(1 / N-\frac{\partial e^{*}}{\partial p^{*}} \frac{\partial p^{*}}{\partial \tilde{A}}\right)-\frac{\partial c_{i}}{\partial e} \frac{\partial e^{*}}{\partial p^{*}} \frac{\partial p^{*}}{\partial \tilde{A}}
$$

which can be reduced by using (3) so that we now have

$$
\frac{\partial \Pi_{i}}{\partial \tilde{A}}=\frac{\partial p^{*}}{\partial \tilde{A}}\left(a_{i}^{*}-e_{i}^{*}\right)+p^{*} / N
$$

Summing this over all firms we get:

$$
\sum_{i=1}^{n} \frac{\partial \Pi_{i}}{\partial \tilde{A}}=p^{*}
$$

substituting this into the regulator's welfare function we obtain:

$$
p^{*}=D^{\prime}(A)
$$

\section{Appendix $\mathrm{C}$}

Proof of Lemma 1:

Proof. Noting $\frac{\partial A}{\partial \tilde{A}}=1+\mu S^{*}\left(1+\frac{\left[1+\varepsilon_{p}\right]}{\left(1-p^{*} \mu \tilde{A}\right)}\right)$ and substituting (20) into (28) yields:

$n p^{*}\left(1+\mu S^{*}\left(1+\frac{\left[1+\varepsilon_{p}\right]}{\left(1-p^{*} \mu \tilde{A}\right)}\right)\right)-\frac{(n-1)}{n} p^{*} \frac{\left[1+\varepsilon_{p}\right]}{\left(1-p^{*} \mu \tilde{A}\right)^{2}}=D^{\prime}(A) 1+\mu S\left(1+\frac{\left[1+\varepsilon_{p}\right]}{\left(1-p^{*} \mu \tilde{A}\right)}\right)$ 
rearranging gives:

$$
p^{*}\left[1-\frac{(n-1)}{n} \frac{\left[1+\varepsilon_{p}\right]}{\left(1+\mu S^{*}\left(1+\frac{\left[1+\varepsilon_{p}\right]}{\left(1-p^{*} \mu \tilde{A}\right)}\right)\right)\left(1-p^{*} \mu \tilde{A}\right)^{2}}\right]=D^{\prime}(A)
$$

as required.

\section{Proof of Lemma 2:}

Proof. By totally differentiating (23) with respect to $\mu$ we obtain:

$$
\frac{d W}{d \mu}=\frac{\partial W}{\partial \mu}+\frac{\partial W}{\partial \tilde{A}^{*}} \frac{d \tilde{A}^{*}}{d \mu}
$$

where $\tilde{A}^{*}$ is the optimally chosen allocation level given by Lemma 1 . Now given the Envelope Theorem, this is reduced to

$$
\frac{d W}{d \mu}=\left.\frac{\partial W}{\partial \mu}\right|_{\tilde{A}=\tilde{A}^{*}}
$$

where we hold $\tilde{A}$ fixed at the optimal level $\tilde{A}^{*}$. This also means that $S^{*}$ is fixed at the optimal level. Working out the components we have:

$$
\frac{\partial \Pi_{i}}{\partial \mu}=\frac{\partial p^{*}}{\partial A^{*}} \frac{\partial A^{*}}{\partial \mu}\left(a_{i}^{*}-e_{i}^{*}\right)+p^{*}\left(\frac{\partial a_{i}^{*}}{\partial A^{*}} \frac{\partial A^{*}}{\partial \mu}-\frac{\partial e^{*}}{\partial p^{*}} \frac{\partial p^{*}}{\partial A^{*}} \frac{\partial A^{*}}{\partial \mu}\right)-\frac{\partial c_{i}}{\partial e^{*}} \frac{\partial e^{*}}{\partial p^{*}} \frac{\partial p^{*}}{\partial A^{*}} \frac{\partial A^{*}}{\partial \mu}
$$

which is simplified to:

$$
\frac{\partial \Pi_{i}}{\partial \mu}=\frac{\partial p^{*}}{\partial A^{*}} \frac{\partial A^{*}}{\partial \mu}\left(a_{i}^{*}-e_{i}^{*}\right)+p^{*} \frac{\partial a_{i}}{\partial A^{*}} \frac{\partial A^{*}}{\partial \mu}
$$

and summing over all firms:

$$
\sum_{i=1}^{n} \frac{\partial \Pi_{i}}{\partial \mu}=p^{*} \sum_{i=1}^{n} \frac{\partial a_{i}^{*}}{\partial A^{*}} \frac{\partial A^{*}}{\partial \mu}=p^{*} \frac{\partial A^{*}}{\partial \mu}
$$

which is substituted in to yield:

$$
\frac{d W}{d \mu}=p^{*} \frac{\partial A^{*}}{\partial \mu}-\frac{\partial S^{*}}{\partial \mu}-D^{\prime}\left(A^{*}\right) \frac{\partial A^{*}}{\partial \mu}
$$

Noting $\frac{\partial A^{*}}{\partial \mu}$ from (1) gives

$$
\frac{d W}{d \mu}=\left[p^{*}-D^{\prime}\left(A^{*}\right)\right] \frac{\partial A^{*}}{\partial \mu}-\frac{\partial S^{*}}{\partial \mu}
$$


where $\frac{\partial S^{*}}{\partial \mu}$ is given by (19).

\section{Appendix D}

\section{Proof of Proposition 2:}

Proof. From Lemma (1), we can solve for the distortion between equilibrium permit price and marginal damage to find:

$$
p^{*}-D^{\prime}(A)=\frac{(n-1)}{n} p^{*} \frac{\left[1+\varepsilon_{p}\right]}{\left(1+\mu S^{*}\left(1+\frac{\left[1+\varepsilon_{p}\right]}{\left(1-p^{*} \mu \tilde{A}\right)}\right)\right)\left(1-p^{*} \mu \tilde{A}\right)^{2}}
$$

and given the equilibrium rent seeking strategy in (17) this can be rearranged to:

$$
p^{*}-D^{\prime}(A)=\frac{S^{*}\left[1+\varepsilon_{p}\right]}{\left(1+\mu S^{*}\left(1+\frac{\left[1+\varepsilon_{p}\right]}{\left(1-p^{*} \mu \tilde{A}\right)}\right)\right)\left(1-p^{*} \mu \tilde{A}^{*}\right) \tilde{A}^{*}}
$$

Similarly we find:

$$
\frac{\partial S^{*}}{\partial \mu}=\frac{S^{*} \Psi}{p^{*}\left(1-p^{*} \mu \tilde{A}\right)}
$$

For both (A3) and (A4) they can be positive or negative. Further, as a consequence of the Envelope Theorem the values of the regulator's initial allocation and firms' rent seeking are fixed at their optimal levels. Hence, we find that

$$
\frac{\partial A^{*}}{\partial \mu}=\tilde{A}^{*} S^{*}
$$

By substituting (A3), (A4) and (A5) into Lemma 2 welfare is improving under an increased responsiveness when:

$$
\frac{S^{*}\left[1+\varepsilon_{p}\right] \tilde{A}^{*} S^{*}}{\left(1+\mu S^{*}\left(1+\frac{\left[1+\varepsilon_{p}\right]}{\left(1-p^{*} \mu \tilde{A}^{*}\right)}\right)\right)\left(1-p^{*} \mu \tilde{A}^{*}\right) \tilde{A}^{*}}-\frac{S^{*} \Psi}{p^{*}\left(1-p^{*} \mu \tilde{A}\right)}>0
$$

multiplying by $\left(1-p^{*} \mu \tilde{A}\right), p^{*}$ and $\left(1+\mu S^{*}\left(1+\frac{\left[1+\varepsilon_{p}\right]}{\left(1-p^{*} \mu \tilde{A}^{*}\right)}\right)\right)$ and dividing by $S^{*}$ this ex- 
pression simplifies to:

$$
p^{*} S^{*}\left[1+\varepsilon_{p}\right]-\Psi\left(1+\mu S^{*}\left(1+\frac{\left[1+\varepsilon_{p}\right]}{\left(1-p^{*} \mu \tilde{A}^{*}\right)}\right)\right)>0
$$

which is rearranged:

$$
p^{*} S^{*}-\Psi+S^{*}\left(p^{*} \varepsilon_{p}-\mu \Psi\left(1+\frac{\left[1+\varepsilon_{p}\right]}{\left(1-p^{*} \mu \tilde{A}^{*}\right)}\right)\right)>0
$$

The third term can be simplified so that

$$
\begin{aligned}
p^{*} \varepsilon_{p}-\mu \Psi\left(1+\frac{\left[1+\varepsilon_{p}\right]}{\left(1-p^{*} \mu \tilde{A}^{*}\right)}\right)= & p^{*} \frac{\partial p^{*}}{\partial \tilde{A}^{*}} \frac{\tilde{A}^{*}}{p^{*}}-\mu\left(\frac{\partial p^{*}}{\partial A^{*}} \frac{\partial A^{*}}{\partial \mu}+\tilde{A}^{*}\left(p^{*}\right)^{2}\right)\left(1+\frac{\left[1+\varepsilon_{p}\right]}{\left(1-p^{*} \mu \tilde{A}^{*}\right)}\right) \\
= & \frac{\partial p^{*}}{\partial \tilde{A}^{*}} \tilde{A}^{*}-\mu\left(\frac{\partial p^{*}}{\partial A^{*}} \tilde{A}^{*} S^{*}+\tilde{A}^{*}\left(p^{*}\right)^{2}\right)- \\
& \mu\left(\frac{\partial p^{*}}{\partial A^{*}} \tilde{A}^{*} S^{*}+\tilde{A}^{*}\left(p^{*}\right)^{2}\right)\left(\frac{\left[1+\varepsilon_{p}\right]}{\left(1-p^{*} \mu \tilde{A}^{*}\right)}\right) \\
= & \tilde{A}^{*}\left(\frac{\partial p^{*}}{\partial \tilde{A}^{*}}-\mu S^{*} \frac{\partial p^{*}}{\partial A^{*}}-\mu\left(p^{*}\right)^{2}\right)- \\
& \tilde{A}^{*}\left(\mu S^{*} \frac{\partial p^{*}}{\partial A^{*}}+\mu\left(p^{*}\right)^{2}\right)\left(\frac{\left[1+\varepsilon_{p}\right]}{\left(1-p^{*} \mu \tilde{A}^{*}\right)}\right)
\end{aligned}
$$

from the chain rule we know that $\frac{\partial p^{*}}{\partial \tilde{A}^{*}}=\frac{\partial p^{*}}{\partial A^{*}} \frac{\partial A^{*}}{\partial \tilde{A}^{*}}=\frac{\partial p^{*}}{\partial A^{*}}\left(1+\mu S^{*}\left(1+\frac{\left[1+\varepsilon_{p}\right]}{\left(1-p^{*} \mu \tilde{A}\right)}\right)\right)$ substituting in we find:

$$
\begin{aligned}
& \tilde{A}^{*}\left(\frac{\partial p^{*}}{\partial A^{*}}\left(1+\mu S^{*}\left(1+\frac{\left[1+\varepsilon_{p}\right]}{\left(1-p^{*} \mu \tilde{A}\right)}\right)\right)-\mu S^{*} \frac{\partial p^{*}}{\partial A^{*}}-\mu\left(p^{*}\right)^{2}\right)- \\
& \tilde{A}^{*}\left(\mu S^{*} \frac{\partial p^{*}}{\partial A^{*}}+\mu\left(p^{*}\right)^{2}\right)\left(\frac{\left[1+\varepsilon_{p}\right]}{\left(1-p^{*} \mu \tilde{A}^{*}\right)}\right) \\
& \Longrightarrow \tilde{A}^{*}\left[\frac{\partial p^{*}}{\partial A^{*}}+\mu S^{*} \frac{\partial p^{*}}{\partial A^{*}}+\mu S^{*} \frac{\partial p^{*}}{\partial A^{*}} \frac{\left[1+\varepsilon_{p}\right]}{\left(1-p^{*} \mu \tilde{A}^{*}\right)}-\right. \\
& \Longrightarrow \tilde{A}^{*}\left[\frac{\partial p^{*}}{\partial A^{*}}-\mu\left(p^{*}\right)^{2}\left(1+\frac{\partial p^{*}}{\partial A^{*}}-\mu\left(p^{*}\right)^{2}-\mu S^{*} \frac{\partial p^{*}}{\partial A^{*}} \frac{\left[1+\varepsilon_{p}\right]}{\left(1-p^{*} \mu \tilde{A}^{*}\right)}-\mu\left(p^{*}\right)^{2} \frac{\left[1+\varepsilon_{p}\right]}{\left(1-p^{*} \mu \tilde{A}^{*}\right)}\right)\right]
\end{aligned}
$$


which gives:

$$
p^{*} \varepsilon_{p}-\mu \Psi\left(1+\frac{\left[1+\varepsilon_{p}\right]}{\left(1-p^{*} \mu \tilde{A}^{*}\right)}\right)=\tilde{A}^{*}\left[\frac{\partial p^{*}}{\partial A^{*}}-\mu\left(p^{*}\right)^{2}\left(1+\frac{\left[1+\varepsilon_{p}\right]}{\left(1-p^{*} \mu \tilde{A}^{*}\right)}\right)\right]
$$

Substituting (A7) into (A6), we obtain the expression:

$$
\begin{array}{r}
p^{*} S^{*}-\Psi+S^{*}\left(p^{*} \varepsilon_{p}-\mu \Psi\left(1+\frac{\left[1+\varepsilon_{p}\right]}{\left(1-p^{*} \mu \tilde{A}^{*}\right)}\right)\right)>0 \\
p^{*} S^{*}-\left(\frac{\partial p^{*}}{\partial A^{*}} \frac{\partial A^{*}}{\partial \mu}+\tilde{A}^{*}\left(p^{*}\right)^{2}\right)+S^{*} \tilde{A}^{*}\left[\frac{\partial p^{*}}{\partial A^{*}}-\mu\left(p^{*}\right)^{2}\left(1+\frac{\left[1+\varepsilon_{p}\right]}{\left(1-p^{*} \mu \tilde{A}^{*}\right)}\right)\right]>0 \\
p^{*} S^{*}-\frac{\partial p^{*}}{\partial A^{*}}\left(S^{*} \tilde{A}^{*}-S^{*} \tilde{A}^{*}\right)-\tilde{A}^{*}\left(p^{*}\right)^{2}+S^{*} \tilde{A}^{*}\left[-\mu\left(p^{*}\right)^{2}\left(1+\frac{\left[1+\varepsilon_{p}\right]}{\left(1-p^{*} \mu \tilde{A}^{*}\right)}\right)\right]>0 \\
p^{*} S^{*}-\tilde{A}^{*}\left(p^{*}\right)^{2}+S^{*} \tilde{A}^{*}\left[-\mu\left(p^{*}\right)^{2}\left(1+\frac{\left[1+\varepsilon_{p}\right]}{\left(1-p^{*} \mu \tilde{A}^{*}\right)}\right)\right]>0 \\
S^{*}-\tilde{A}^{*} p^{*}+S^{*} \tilde{A}^{*}\left[-\mu p^{*}\left(1+\frac{\left[1+\varepsilon_{p}\right]}{\left(1-p^{*} \mu \tilde{A}^{*}\right)}\right)\right]> \\
>
\end{array}
$$

which yields:

$$
S^{*}>\frac{\tilde{A}^{*} p^{*}}{\left[\frac{\left(1-p^{*} \mu \tilde{A}^{*}\right)^{2}-\tilde{A}^{*} \mu p^{*}\left[1+\varepsilon_{p}\right]}{\left(1-p^{*} \mu \tilde{A}^{*}\right)}\right]}
$$

Hence, from (17) we know that for welfare to increase given an increase in responsiveness the following must hold:

$$
\begin{aligned}
S^{*} & \equiv \frac{(n-1)}{n} \frac{\tilde{A}^{*} p^{*}}{\left(1-p^{*} \mu \tilde{A}^{*}\right)}>\frac{\tilde{A}^{*} p^{*}}{\left[\frac{\left(1-p^{*} \mu \tilde{A}^{*}\right)^{2}-\tilde{A}^{*} \mu p^{*}\left[1+\varepsilon_{p}\right]}{\left(1-p^{*} \mu \tilde{A}^{*}\right)}\right]} \\
& \Longrightarrow \frac{(n-1)}{n}>\frac{\left(1-p^{*} \mu \tilde{A}^{*}\right)^{2}}{\left(1-p^{*} \mu \tilde{A}^{*}\right)^{2}-p^{*} \mu \tilde{A}^{*}\left[1+\varepsilon_{p}\right]}
\end{aligned}
$$


this does not hold when $\left|\varepsilon_{p}\right|<1$ so that welfare is decreasing in regulatory responsiveness. However, for $\left|\varepsilon_{p}\right|>1$ It follows that increasing regulatory responsiveness is ambiguous and depends on the value of $\left|\varepsilon_{p}\right|$.

\section{Proof of Corollary 2:}

Proof. The regulator's payoff from aggregate rent seeking is given by $(\beta-1) S^{*}$. Substituting $(\beta-1) \frac{\partial S^{*}}{\partial \tilde{A}}$ for $\frac{\partial S^{*}}{\partial \tilde{A}}$ in the proof of Lemma 1 yields the results.

\section{Proof of Proposition 3:}

Proof. Substituting $(\beta-1) \frac{\partial S^{*}}{\partial \mu}$ into Lemma 2 yields:

$$
\frac{d W}{d \mu}=\left[p^{*}-D^{\prime}\left(A^{*}\right)\right] \frac{\partial A^{*}}{\partial \mu}+(\beta-1) \frac{\partial S^{*}}{\partial \mu}
$$

Substituting (31) into (A8) and noting the similarity to Proposition 2 we obtain:

$$
\frac{-(\beta-1) S^{*}\left[1+\varepsilon_{p}\right] \tilde{A}^{*} S^{*}}{\left(1+\mu S^{*}\left(1+\frac{\left[1+\varepsilon_{p}\right]}{\left(1-p^{*} \mu \tilde{A}^{*}\right)}\right)\right)\left(1-p^{*} \mu \tilde{A}^{*}\right) \tilde{A}^{*}}+\frac{(\beta-1) S^{*} \Psi}{p^{*}\left(1-p^{*} \mu \tilde{A}\right)}>^{<} 0
$$

we can be rearranged to give:

$$
p^{*} S^{*}\left[1+\varepsilon_{p}\right]-\Psi\left(1+\mu S^{*}\left(1+\frac{\left[1+\varepsilon_{p}\right]}{\left(1-p^{*} \mu \tilde{A}^{*}\right)}\right)\right) \underset{<}{>} 0
$$

The results follow from the proof given in Proposition 2. 